\title{
Transformation-mediated exchange of virulence determinants by co-cultivation of pathogenic Neisseriae
}

\author{
Matthias Frosch ${ }^{a}$ and Thomas F. Meyer ${ }^{b}$ \\ ${ }^{a}$ Institut für Medizinische Mikrobiologie, Medizinische Hochschule Hannover, \\ Hannover, FRG, and ${ }^{b}$ Max-Planck-Institut für Biologie, Abteilung Infektionsbiologie, Tübingen, FRG
}

Received 24 June 1992

Accepted 30 June 1992

Key words: Neisseria; Transformation; Virulence determinants

\section{SUMMARY}

The horizontal flow of genetic material between microbes utilizes three principal routes: conjugation, transduction and transformation. While the significance in nature of the first two pathways is generally accepted, the in vivo role of transformation remains uncertain, despite the early observations by Griffith in 1928 on the transformation of streptococci from an avirulent to a virulent state [1]. Recently, circumstantial evidence was collected suggesting a role for transformation-mediated horizontal exchange in the modulation of virulence determinants of pathogenic Neisseriae and the variation of surface structures. In order to further assess the significance of transformation-mediated exchange we performed simple co-cultivation experiments of different Neisseria strains. We observed an efficient intra- and interspecies transfer of essential virulence determinants; the process was sensitive

Correspondence to: T.F. Meyer, Max-Planck-Institut für Biologie, Abteilung Infektionsbiologie, Spemannstr. 34, W-7400 Tübingen, FRG. to the presence of DNaseI in the culture and was blocked in transformation-deficient recipients.

\section{INTRODUCTION}

The pathogenic Neisseriae, i.e. $N$. gonorrhoeae and $N$. meningitidis, representing Gram-negative diplococci, infect humans as their sole natural host. Several non-pathogenic, commensal Neisseria species also exist which still carry some of the putative neisserial virulence determinants, such as opa, pil, and lip [2]. Like many other bacterial species, the pathogenic Neisseriae are naturally competent for genetic transformation $[3,4]$. This process is very efficient, involving a number of bacterial functions including the major pilus subunit, PilE [5] and an intact dudl locus [6]. In order to allow efficient DNA uptake, the bacteria must recognize a specific sequence motif in the transforming DNA [7], which often represents part of the structure of transcriptional terminators, as in the case of the opa, iga and ctr genes [8-11]. The uptake of DNA into the bacterial cytoplasm occurs via linear intermediates [6]. Subsequent incorporation into the chromosome 
or re-circularization of plasmids therefore requires RecA-dependent homologous recombination. Both the uptake specificity and the recombination requirement imply that only species-related DNA can be stably accomodated in a recipient cell. The various restriction modification systems existing in Neisseriae [12] may impose additional constraints on the transformation process.

Recent in vitro experiments suggest a role for natural transformation in the phase and antigenic variation of the $N$. gonorrhoeae pilin [5,13] although pilin variation can also occur by an alternative intracellular pathway [5,14] (for review see ref. 15). Moreover, the observation of mosaic genes, such as iga and penA [9,16], provides strong evidence for an ongoing process of horizontal exchange among various Neisseria species. The association of DNA uptake sequences with such virulence determinants suggests that horizontal exchange may be driven by transformation. Conversely, transducing phage or conjugative systems that would allow the mobilization of chromosomal genes have not been reported for Neisseriae. We therefore set out in this investigation to further elucidate the potential significance of transformation as a mediator of genetic exchange in vivo. Due to the restricted host specificity of the pathogenic and most commensal Neisseria species, and their inability to multiply and survive outside their host, this addresses the question of whether transformation is likely to occur during the course of an infection.

In order to assess the transformation-mediated exchange between two Neisseria strains, we chose different chromosomal determinants, all of which have been implicated in pathogenesis: the iga determinant, a single copy gene present in both gonococci and meningococci, codes for an extracellular enzyme that specifically cleaves human IgA1 antibody [17,18]. The opa determinants constitute a family of polymorphic genes which are present in about 11, three to four, and up to two copies in gonococci, meningococci, and certain commensal isolates, respectively $[2,9,10]$; these genes encode phase variable outer membrane proteins that play essential roles in the interaction with human epithelial cells or polymorphonuclear leukocytes ([19,21]; E.M. Kupsch, B.
Knepper, T. Kuroki, I. Hener and T.F. Meyer, submitted). A third virulence determinant used in these studies are the capsule-synthesis genes of $N$. meningitidis (cps) which are absent in gonococci but present in several commensal species [22]. They are essential for the production of a capsule which is composed of acidic polysaccharides. The capsular types of $N$. meningitidis differ in their chemical composition and their immunological characteristics, a single strain, however, has only a single capsule-gene locus [22].

\section{RESULTS AND DISCUSSION}

In a first set of experiments, two $N$. gonorrhoeae MS11 strains were co-cultivated in order to assess the genetic transfer of the opaE locus [23]. The donor N246 carried an insertion of the erm C determinant derived from Bacillus subtilis [24] in the ClaI site of the N. gonorrhoeae MS11 opaE gene [9], and carried, in addition, a $\operatorname{rec} A$ locus partially replaced by the $\mathrm{cat}_{\mathrm{GC}}$ cassette to abolish its own transformation competence (D. Facius and C.P. Gibbs, unpublished) [25]. The transformation-competent recipient $\mathrm{N} 248$ was an S-pilin variant of strain MS11 [5] and carried two chromosomal markers, al $^{\mathrm{r}}$ and rif $^{\mathrm{r}}$. Donor and recipient strains were first grown separately and then combined at an $\mathrm{OD}_{550}$ of about 0.2. From the combined culture, aliquots were taken at serveral time points in order to determine the number of $\mathrm{Erm}^{\mathrm{r}}$ transformants resulting from the transfer of the opaE::ermC determinant from the donor to the recipient. As shown in Fig. 1, efficient marker transfer occurred as early as $15 \mathrm{~min}$ after combining the cultures, reaching a maximum of $10^{-5} \mathrm{Erm}^{\mathrm{r}}$ transformants per recipient cells after $2 \mathrm{~h}$ of co-cultivation. No $\mathrm{Erm}^{\mathrm{r}}$ transformants were obtained by co-cultivation of donor and recipient in the presence of DNaseI, indicating that the observed marker exchange resulted from transformation. Genomic DNA of individual transformants was prepared to confirm by Southern hybridization that the ermC marker was inserted in one of the recipient's opa loci (data not shown). This provided evidence for recombinant opa loci that were generated simply by co-cultivation of the two strains. 


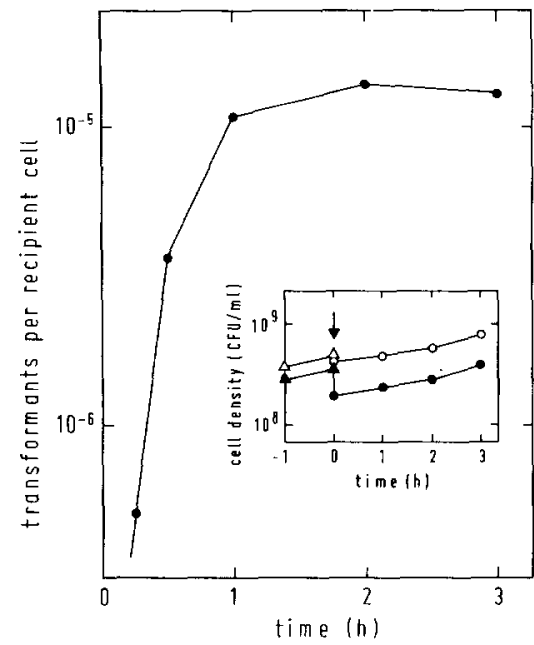

Fig. 1. Kinetics of Erm ${ }^{\mathrm{r}}$-resistance-marker transfer between two co-cultivated $N$. gonorrhoeae strains. Figure insert: growth curves of the MS11-N246 donor strain (opaE::ermC, recA::cat ${ }_{\mathrm{GC}}$; open symbols) and the MS11-N248 recipient (S[ = S-pilin], nal ${ }^{\mathrm{r}}$, rif ${ }^{\mathrm{r}}$; filled symbols), cultured in proteose peptone transformation medium containing $10 \mathrm{mM} \mathrm{MgCl}_{2}$ $[5,25]$. At zero time, the two separate cultures (triangles) were combined (circles); the number of donor and recipient cells in the combined culture was determined on the basis of resistances expressed. Main figure: ratio between $\operatorname{Erm}^{\mathrm{r}}(7 \mu \mathrm{g} / \mathrm{ml})$, $\mathrm{Nal}^{\mathrm{r}}(6 \mu \mathrm{g} / \mathrm{ml}), \operatorname{Rif}^{\mathrm{r}}(100 \mu \mathrm{g} / \mathrm{ml})$ transformants and recipient cells. Erm ${ }^{r}$ resistant transformants were selected for on plates containing DNaseI $(30 \mu \mathrm{g} / \mathrm{ml})$ in order to abrogate transformation after plating. In the presence of $40 \mu \mathrm{g} / \mathrm{ml}$ DNaseI in the culture the number of transformants was below $10^{-8}$.

Equivalent results were obtained using donor strain N247, identical with N246 except that it carried the ermC insertion in the $B g l$ II site of the IgA protease locus (iga) [9] (D. Facius, unpublished). With this strain the overall efficiency of the marker transfer was three-fold lower as compared with the opaE::ermC donor N246, a slight difference which may in part reflect the fact that iga represents a single copy gene in contrast to opa.

Next we asked for the possibility of interspecies exchanges of related genes by assaying for the DNase-sensitive transfer of the opaE::ermC determinant from gonococci to the non-capsulated group $B$ meningococcal recipient $\mathrm{N} 215$ $\left(\right.$ cps $^{-}$, nal $^{\mathrm{r}}$, rif $\left.^{\mathrm{r}}\right)$ [26]. In these experiments we measured transformation frequencies in the order of $10^{-6}$, suggesting that opa genes can be readily exchanged via transformation also between the two pathogenic species. In addition, evidence for the occurrence of this process was obtained for combinations of pathogenic and commensal Neisseria species (data not shown).

Another series of experiments was concerned with the question of whether the capsular polysaccharide phenotype of $N$. meningitidis can be altered by transformation. The cps gene complex is organized in distinct regions coding general functions including regulation, subunit polymerisation and transport. The biosynthesis determinant for the serotype-specific building blocks is spatially separated within the cps complex and differs from the equivalent region of other serotype isolates [22]. Conceivably, exchange of the serotype-specific fragment (region A) should lead to serotype conversion and this might possibly occur by transformation. To test this hypothesis, we performed a co-cultivation experiment using a serogroup W135 $N$. meningitidis strain as donor and a serogroup B strain as recipient. The latter carried chromosomal nal $^{\mathrm{r}}$ and rif $^{\mathrm{r}}$ markers while the donor was transformation-incompetent and carried an insertion of ermC in region D. Thus, the insertion was located adjacent to the region of interest, i.e. the serotype-specific region $\mathrm{A}$, different to above described experiments involving opa and iga. The insertion did not affect the capsular polysaccharide phenotype expression. Upon co-cultivation for a period of $2 \mathrm{~h}$, according to the above described protocol, Erm ${ }^{\mathrm{r}}$, Rif ${ }^{\mathrm{r}}$ and $\mathrm{Nal}^{\mathrm{T}}$ colonies grew up at a frequency of $5 \times 10^{-6}$. About one third of the transformants, which originally belonged to serogroup $B$, now reacted with a monoclonal antibody specific for the serogroup W135 meningococcal capsular polysaccharide. The remaining Erm ${ }^{\mathrm{r}}$ transformants still produced the authentic serogroup B capsule indicating that these cells had only acquired the $\mathrm{erm}^{\mathrm{r}}$ marker linked with region $D$ and not the adjacent serogroup-specific region A of the W135 donor. Since no colonies with the triple resistance were obtained by cultivation in the presence of DNaseI the process was based on transformation.

The serogroup-converted transformants were investigated by Southern-blot analysis, using the cloned $c p s$ gene cluster of a serogroup B strain as 
probe (Fig. 2). All transformants showed restriction patterns significantly different from both the serogroup W135 donor and the serogroup B recipient: in clone W1, for example, two HindIII fragments with sizes of about $9.5 \mathrm{~kb}$ each and a 3.8-kb fragment representing the serogroupspecific region $A$, characteristically found in the cps locus of the serogroup B meningococcal strain [22], were replaced by $20-\mathrm{kb}, 8-\mathrm{kb}$ and $2-\mathrm{kb}$ HindIII fragments of the serogroup W135 strain. In contrast, transformant W2 exhibited only minor changes in the cps locus that were still sufficient to alter the capsular polysaccharide phenotype, i.e. the region A-specific $3.8-\mathrm{kb}$ HindIII fragment and a 9.5-kb HindIII fragment

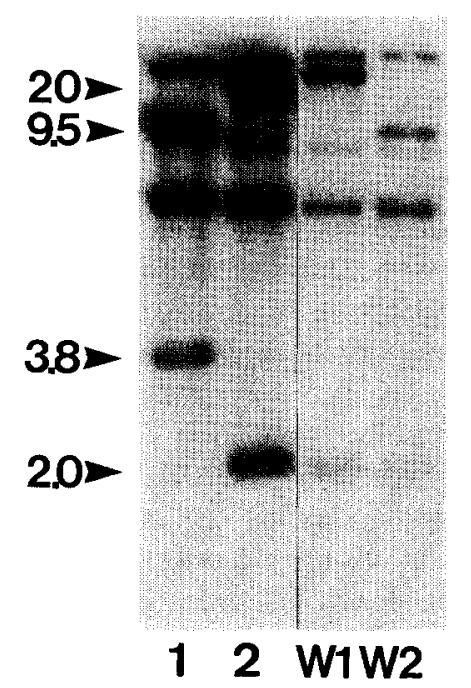

Fig. 2. Southern-blot hybridization of $N$. meningitidis chromosomal DNA using the cloned cps gene cluster as probe. DNA samples were cleaved using HindIII: lane 1, serogroup Bspecific recipient strain derived from $N$. meningitidis B1940, U. Berger, Heidelberg; lane 2, serogroup W135-specific donor strain derived from $N$. meningitidis W135, American Type Culture Collection; lanes $\mathrm{W} 1$ and $\mathrm{W} 2$, two $\mathrm{Erm}^{\mathrm{r}}$ transformants. Hybridization was performed with digoxigenin-labelled plasmid pMF32.35, which harbours the complete cps locus of $N$. meningitidis B1940 [22]. Size markers in kilobase pairs (kb) are indicated on the left. The $3.8-\mathrm{kb}$ fragment of the strain recipient (lane 1) corresponds to the biosynthesis region $\mathrm{A}$ and one of the $9.5-\mathrm{kb}$ fragments corresponds to region $\mathrm{D}$ and the major part of region $B$ [22]. Thus, loss of the $3.8-\mathrm{kb}$ HindIII fragments in the Erm ${ }^{\mathrm{r}}$ transformants (W1 and $\mathrm{W} 2$ ), as compared with the recipient (lane 1), reflects changes in the capsular polysaccharide phenotype of the transformants.

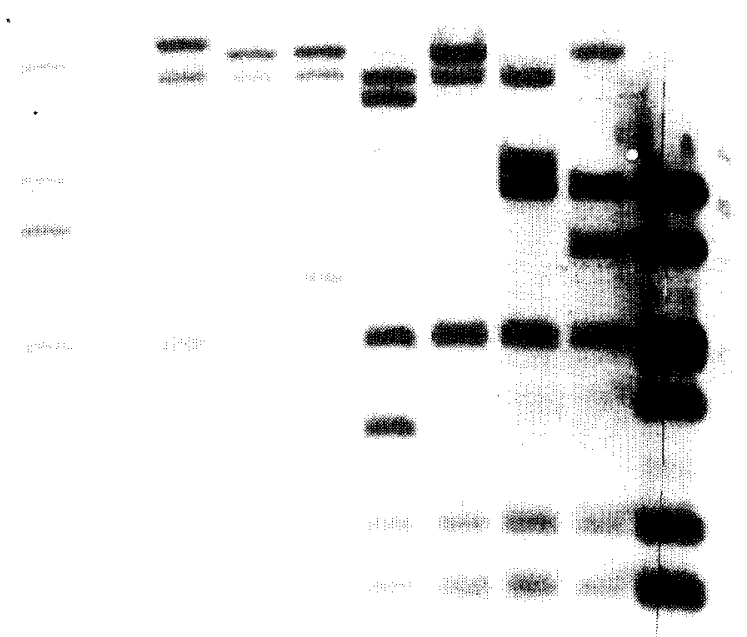

\section{$\begin{array}{llllllllll}1 & 2 & 3 & 4 & 5 & 6 & 7 & 8 & 9 & 10\end{array}$}

Fig. 3. Southern-blot hybridization of EcoRI-digested chromosomal DNA of natural $N$. meningitidis serogroup B isolates. Strains were isolated in the diagnostic laboratories of the Institut für Medizinische Mikrobiologie, Hannover (lanes 1-9). Lane 10 represents the cloned plasmid pMF32.35 [22].

Digoxigenin-labelled plasmid pMF32.35 was used as probe.

were replaced by the $2-\mathrm{kb}$ and 8 -kb fragments of the W135 strain (Fig. 2).

Among the transformants several different restriction patterns were observed. This phenomenon appears plausible in the context of restriction-site polymorphisms in the cps complexes of different serogroup isolates [11]. In the described experiment it also reflects the fact that different transformants have acquired different portions of the cps gene cluster from the donor strain. If transformation-driven exchanges of $c p s$ genes play a role in vivo, similar polymorphisms in the cps gene cluster of naturally isolated group $B$ meningococci should be seen. That this is in fact the case is shown in Fig. 3, which indicates a fundamental difference to Escherichia coli where even different serotypes exhibit very similar restriction patterns [27]. These observations, and furthermore the occurrence of meningococcal isolates possessing different capsular types within a single clonal type [28], provide strong evidence 
for an ongoing horizontal exchange process in vivo, involving parts of the cps gene cluster.

Our data demonstrate a remarkable efficiency and versatility of transformation-mediated processes in a Neisseria culture. Transformation hence may play a significant role in nature and cause the reassortment of virulence determinants among members of the genus Neisseria $[9,16,20,31]$. In fact, no other known genetic exchange mechanism exists in Neisseriae that could account for the observed in vivo phenomena.

Transformation-mediated exchange may allow pathogenic organisms to adapt to their host, but may also incidentally enhance their pathogenic potential. For example, only some capsular types have strong pathogenic potential and are preferentially associated with meningitis [29]. Up to $30 \%$ of the human population carry meningococci in their nasopharyngeal tract without being diseased. This typical situation then reflects a proper balance between the infectious agent and its host. By occasional horizontal exchange and gene reassortment, in individuals being superinfected by a second Neisseria strain, new situations may arise that mark the beginning of local outbreaks and epidemics [30].

\section{ACKNOWLEDGEMENTS}

We would like to thank Elke Schultz for excellent assistance in the performance of numerous co-cultivation experiments and Dr. Brian Robertson for comments on the manuscript.

\section{REFERENCES}

[1] Griffith, F. (1928) J. Hyg. (London) 27, 113-118.

[2] Aho, E.L., Murphy, G.L. and Cannon, J.G. (1987) Infect. Immun. 55, 1009-1013.

[3] Sparling, P.F. (1966) J. Bacteriol. 92, 1364-1370.

[4] Smith, H.O., Danner, D.B. and Deich, R.A. (1981) Annu. Rev. Biochem. 50, 41-68.

[5] Gibbs, C.P., Reimann, B.-Y., Schultz, E., Kaufmann, A.,
Haas, R. and Meyer, T.F. (1989) Nature (London) 338, 651-652.

[6] Biswas, G.D., Lacks, S.A. and Sparling, P.F. (1989) J. Bacteriol. 171, 657-664.

[7] Goodman, S.D. and Scocca, J.J. (1988) Proc. Natl. Acad. Sci. USA 85, 6982-6986.

[8] Stern, A., Brown, M., Nickel, P. and Meyer, T.F. (1986) Cell 47, 61-71.

[9] Halter, R., Pohlner, J. and Meyer, T.F. (1989) EMBO J. 8, 2737-2744.

[10] Stern, A. and Meyer, T.F. (1987) Mol. Microbiol. 1, 5-12.

[11] Frosch, M., Edwards, U., Bousset, K., Krau $\beta$ e, B., and Weisgerber, C. (1991) Mol. Microbiol. 5, 1251-1263.

[12] Stein, D.C., Gregoire, S. and Piekarowicz, A. (1988) Infect. Immun. 56, 112-116.

[13] Seifert, H.S., Ajioka, R.S., Marchal, C., Sparling, P.F. and So, M. (1988) Nature (London) 336, 392-395.

[14] Swanson, J., Morrison, S., Barrera, O. and Hill, S. (1990) J. Exp. Med. 171, 2131-2139.

[15] Meyer, T.F., Gibbs, C.P. and Haas, R. (1990) Annu. Rev. Microbiol. 44, 451-477.

[16] Spratt, B.G., Zhang, Q.-Y., Jones, D.M., Hutchinson, A., Brannigan, J.A. and Dowson, C.G. (1989) Proc. Natl. Acad. Sci. USA 86, 8988-8992.

[17] Plaut, A.G., Artenstein, M.S. and Capra, J.D. (1975) Science 190, 1103-1105.

[18] Pohlner, J., Halter, R., Beyreuther, K. and Meyer, T.F. (1987) Nature 325, 458-462.

[19] Makino, S., van Putten, J.P.M. and Meyer, T.F. (1991) EMBO J. 10, 1307-1315.

[20] Haas, R., Veit, S. and Meyer, T.F. (1992) Mol. Microbiol. 6, 197-208.

[21] Rest, F.R. and Frangipane, J.V. (1992) Infect. Immun. 60, 989-997.

[22] Frosch, M., Weisgerber, C. and Meyer, T.F. (1989) Proc. Natl. Acad. Sci. USA 86, 1669-1673.

[23] Bihlmaier, A., Römling, U., Meyer, T.F., Tümmler, B. and Gibbs, C.P. (1991) Mol. Microbiol. 5, 2529-2539.

[24] Projan, S.J., Monod, M., Narayanan, C.S. and Dubnau, D. (1987) J. Bacteriol. 169, 5131-5139.

[25] Rudel, T., van Putten, J.P.M., Gibbs, C.P., Haas, R. and Meyer, T.F. (1992) Mol. Microbiol. 6, in press.

[26] Frosch, M., Schultz, E., Glenn-Calvo, E. and Meyer, T.F. (1990) Mol. Microbiol. 4, 1215-1218.

[27] Roberts, I., Mountford, R., High, N., Bitter-Suermann, D., Jann, K., Timmis, K.N. and Boulnois, G.J. (1986) J. Bacteriol. 168, 1228-1233.

[28] Caugant, D.A., Froholm, L.O., Bovre, K., Holten, E., Frasch, C.E., Mocca, L.F., Zollinger, W.D. and Selander, R.K. (1986) Proc. Natl. Acad. Sci. USA 83, 4927-4931.

[29] Devoe, I.W. (1982) Microbiol Rev. 46, 162-190.

[30] Achtman, M. (1990) Rev. Med. Microbiol. 1, 29-38.

[31] Feavers, I.M., Heath, A.B., Bygraves, J.A. and Maiden, M.C.J. (1992) Mol. Microbiol. 6, 489-496. 